DOI 10. 18307/2017. 0508

(C) 2017 by Journal of Lake Sciences

\title{
长江中下游典型浅水湖泊沉积物一水界面磷与铁的耦合关系
}

\author{
龚梦丹 ${ }^{1,2}$, 金增锋 ${ }^{1,2}$, 王 燕 ${ }^{1,2}$, 林 娟 ${ }^{1,2}, 丁 士$ 明 $^{1 * *}$ \\ (1: 中国科学院南京地理与湖泊研究所湖泊与环境国家重点实验室,南京 210008) \\ (2: 中国科学院大学, 北京 100049)
}

\begin{abstract}
摘 要: 目前普遍认为磷铁耦合关系是 $\mathrm{P}$ 迁移的主要机制, 但大部分研究结果并未提供直接的原位证据. 为了探索沉积 物剖面磷 (P) 与铁 $(\mathrm{Fe})$ 的耦合关系, 利用 ZrO-Chelex 薄膜扩散梯度技术 (ZrO-Chelex DGT), 分别对太湖、巢湖、鄱阳湖和 洞庭湖 4 个浅水湖泊沉积物有效态 $\mathrm{Fe}$ 和 $\mathrm{P}$ 进行高分辨采样和分析. 结果表明, 不同湖区有效态 $\mathrm{Fe}$ 和 $\mathrm{P}$ 浓度在沉积物水界面处开始增加,之后波动变化, 垂向异质性较强, 但两者浓度变化同步. 有效态 $\mathrm{P}$ 和 $\mathrm{Fe}$ 浓度的相关分析结果证明两 者浓度具有显著的线性相关. 室内厌氧培养实验进一步表明, $\mathrm{Fe}^{3+}$ 的还原性促使 $\mathrm{Fe}^{2+}$ 与铁结合态磷的释放, 促使 DGT 有 效态 $\mathrm{P}$ 与 $\mathrm{Fe}$ 同步变化. 该结果表明沉积物 $\mathrm{P}$ 的二次迁移和释放受 $\mathrm{Fe}$ 氧化还原过程的控制, 为铁磷耦合关系提供了直接 证据.
\end{abstract}

关键词: 沉积物; 薄膜扩散梯度; 铁磷耦合; 内源; 有效性; 长江中下游

\section{Coupling between iron and phosphorus in sediments of shallow lakes in the middle and lower reaches of Yangtze River using diffusive gradients in thin films (DGT)}

\author{
GONG Mengdan ${ }^{1,2}$, JIN Zengfeng ${ }^{1,2}$, WANG Yan $^{1,2}$, LIN Juan ${ }^{1,2}$ \& DING Shiming ${ }^{1 * *}$ \\ (1: State Key Laboratory of Lake Science and Environment, Nanjing Institute of Geography and Limnology, Chinese Academy \\ of Sciences, Nanjing 210008, P.R.China) \\ (2: University of Chinese Academy of Sciences, Beijing 100049, P.R.China)
}

\begin{abstract}
It is universally accepted that the coupling relationship between phosphorus $(\mathrm{P})$ and iron ( Fe) is responsible for the migration of $\mathrm{P}$, but there is little direct in situ evidence. In order to investigate the coupling relationship between $\mathrm{P}$ and Fe in sediments of shallow lakes, the concentrations of labile $\mathrm{P}$ and Fe in the sediments in Lakes Taihu, Chaohu, Poyang and Dongting were measured using ZrO-Chelex diffusive gradients in thin films (ZrO-Chelex DGT). The results showed that both labile Fe and P began to increase downward below the sediment-water surface followed by fluctuation up to the bottom of the sediment profiles. Their changes were consistent along the profiles, which were further supported by the positively linear correlations among them. Anaerobic incubation experiment further showed that the reductive dissolution of iron oxides led to the releases of ferrous Fe and P associated with iron oxides. The results proved that the remobilization of $\mathrm{P}$ in sediments was dominated by Fe redox.
\end{abstract}

Keywords: Sediment; diffusive gradients in thin films; Fe-P coupling; internal loading; availability; middle and lower reaches of Yangtze River

湖泊沉积物是水体氮、磷等营养盐重要的汇, 由于浅水湖泊易受风浪扰动作用发生再悬浮, 造成沉积物 氮、磷等营养物质释放到上覆水, 因此比深水湖泊更易引起湖泊富营养化 ${ }^{[1]}$. 目前太湖和巢湖等多个浅水湖 泊面临水质恶化和湖泊富营养化等问题 ${ }^{[2-4]}$. 研究表明, 磷 $(\mathrm{P})$ 是湖泊蓝藻水华产生的限制性因子 ${ }^{[5]}$, 内源 $\mathrm{P}$ 的释放是切断外源污染后, 富营养化现象持续存在的重要原因 ${ }^{[6-8]}$.

在探讨内源 P 释放机制时, 铁、铝、钲结合态磷 ( Ca-P、Al-P、Fe-P) 等都纳人研究范围, 其中 Fe-P 是沉积

* 国家水体污染控制与治理科技重大专项 (2012ZX07103-005) 资助. 2016-09-07 收稿; 2016-12-07 收修改稿. 龚梦丹( $1990 \sim$ ), 女, 硕士研究生; E-mail: mengdan_rainbow@163.com.

** 通信作者; E-mail: smding@ niglas.ac.cn. 
物中最易受环境影响而引起磷释放的形态 ${ }^{[9]}$. 目前, 大量研究围绕沉积物 Fe 和 P 的关系展开 ${ }^{[10-12]}$. Bortleson 等 ${ }^{[13]}$ 研究发现湖泊沉积物中 $\mathrm{P}$ 和 $\mathrm{Fe}$ 呈现显著的相关性. 进一步的研究表明, Fe 含量高的沉积物, $\mathrm{NH}_{4} \mathrm{Cl}-\mathrm{P}$ 、 $\mathrm{NaOH}-\mathrm{P}$ 浓度相对也高 ${ }^{[14]}$. Søndergaard 等 $^{[15]}$ 对丹麦浅水湖泊沉积物进行 $\mathrm{P}$ 形态分析时, 提出沉积物表层 $\mathrm{P}$ 浓度受外源 $\mathrm{P}$ 负荷和 $\mathrm{Fe}$ 浓度影响, 且随着两者浓度增加而增加. 另外也有研究表明 $\mathrm{P}$ 的释放与 $\mathrm{P} / \mathrm{Fe}$ 比值 呈负相关, 在 $\mathrm{P} / \mathrm{Fe}<1$ 时, $\mathrm{P}$ 的释放速度明显升高 ${ }^{[16]}$. 这些发现都验证了 $\mathrm{Fe}$ 和 $\mathrm{P}$ 的循环对 $\mathrm{P}$ 的界面释放起 重要作用, $\mathrm{Fe}^{3+}$ 的降低对 $\mathrm{P}$ 释放具有主导作用,在高 $\mathrm{P}$ 水平下沉积物中 $\mathrm{Fe}$ 与 $\mathrm{P}$ 的关系更加密切 ${ }^{[17]}$.

目前有关沉积物的研究主要基于主动采样技术, 采样和运输过程会破坏沉积物原有性质, 改变沉积物 氧化还原条件 ${ }^{[18]}$, 且分辨率低 ( $\mathrm{cm}$ 级别), 分析测定步骤繁琐且速度较慢. 新型原位被动采样技术 $\mathrm{ZrO}$ Chelex 薄膜扩散梯度技术 (ZrO-Chelex DGT), 可以在不破坏沉积物情况下, 能够原位同步获取沉积物剖面有 效态 $\mathrm{P}$ 和 $\mathrm{Fe}$ 的信息, 分辨率达到毫米级. $\mathrm{Xu}$ 等 ${ }^{[19]}$ 和 Sun 等 ${ }^{[20]}$ 通过室内模拟实验证明 ZrO-Chelex DGT 在自 然界正常水体下能够同时测量沉积物剖面有效态 P 和 Fe 浓度,且其对这两种离子的检测极限浓度较高.

本研究选取长江中下游地区典型浅水湖泊太湖、巢湖、鄱阳湖和洞庭湖这 4 个湖泊为研究对象, 利用 ZrO-Chelex DGT 同步获取现场沉积物一水界面有效态 P 和 Fe 浓度的剖面分布信息, 并对两者的变化进行分 析,同时进行室内模拟实验,进一步明确铁磷耦合关系, 为内源磷释放机理提供直接证据.

\section{1 材料和方法}

\section{1 研究区概况}

太湖、巢湖、鄱阳湖和洞庭湖为中国四大淡水湖泊,他们分别位于江苏省南部、安徽省江淮丘陵中部、江 西省北部以及湖南省东北部, 其面积分别为 $2328 、 760 、 2933$ 和 $2625 \mathrm{~km}^{2}$, 平均深度分别为 1.9、2.7、5.1 和 6.4 $\mathrm{m}$. 湖泊土壤类型基本为 $\mathrm{Fe} 、 \mathrm{Mn}$ 元素富集的红壤或黄壤, 湖水矿化度较高, 主要为以 $\mathrm{Ca}^{2+}$ 为主的阳离子以及 以 $\mathrm{HCO}_{3}^{-}$为主的阴离子, 其 $\mathrm{pH}$ 偏弱碱性, 这些性质为蓝藻生长提供了适宜的环境 ${ }^{[21]}$. 研究表明, 这些湖泊均 存在富营养化现象,且主要受农业非点源污染以及工业废水排放点源污染所致 ${ }^{[22]}$.

\subsection{ZrO-Chelex DGT 技术原理和装置准备}

薄膜梯度扩散技术 (DGT) 作为一种原位被动采样技术, 由 Davison 等于 1994 年发明 ${ }^{[23]}$. 该技术是以费 克第一扩散定律为理论基础, 当装置投放至水体或沉积物中, 环境中自由态离子通过滤膜和扩散膜组成的 扩散层,进而被固定膜捕获并累积, 根据通量与费克第一定律公式计算出 DGT 有效浓度 ${ }^{[24]}$.

ZrO-Chelex DGT 是在氧化锆 DGT( Zr-oxide DGT) 基础上发展起来的复合 DGT, 利用 ZrO-Chelex 凝胶层 作为同步固定 $\mathrm{Fe} 、 \mathrm{P}$ 的固定层 ${ }^{[19,25]}$, 其容量较高 ${ }^{[19]}$, 还可同时测定 $\mathrm{P}$ 和 $\mathrm{As}^{5+} 、 \mathrm{Cr}^{6+} 、 \mathrm{Mo}^{6+} 、 \mathrm{Sb}^{5+} 、 \mathrm{Se}^{6+} 、 \mathrm{~V}^{5+} 、 \mathrm{~W}^{6+}$ 等重金属离子 ${ }^{[26-27]}$. ZrO-Chelex DGT 购置于南京智感环境科技有限公司, 采用了新型平板 DGT 塑料外 套 ${ }^{[28]}$, 固定膜的配制方法参考文献 [19], 扩散膜为 $1.5 \%$ 琼脂糖, 厚度为 $0.8 \mathrm{~mm}$, 滤膜为 PVDF 膜 ( $0.45 \mu \mathrm{m}$, 厚度为 $0.1 \mathrm{~mm}$ ). 组装 DGT 装置时, 首先将固定膜放置在底板上, 之后依次放置扩散膜和滤膜, 最后盖板固 定 3 层膜, 置于去离子水充氮去氧 $16 \mathrm{~h}$ 备用.

\section{3 样品采集与分析方法}

1.3.1 样品采集 2015 年 5-7 月, 依次在太湖、巢湖、鄱阳湖和洞庭湖进行 DGT 装置投放和现场表层泥取 样, 其采样点分布见图 1. 通过重力投放器, 将 DGT 装置投放到采样点湖区沉积物中, $24 \mathrm{~h}$ 后回收 DGT 装置, 标记沉积物一水界面, 用去离子水冲洗装置表面沉积物, 装人自封袋保持湿润, 带回实验室进行分析. 采集太 湖梅梁湾柱状样品和水样,低温保存带回实验室. 其中柱状样进行现场分层,用于室内培养实验.

1.3.2 室内培养实验 将太湖梅梁湾分层泥进行相同层次的混匀过笁, 按沉积物分层顺序分装成 4 个平行沉 积物柱状样, 并添加上覆水 (原位过滤水样), 恒温 $25^{\circ} \mathrm{C}$ 下淹水培养. 室内模拟好氧一厌氧环境, 首先将稳定 后的沉积物间断曝气使其充分好氧, 随后加盖子密封, 使沉积物逐渐厌氧, 每天定时监测上覆水溶解氧浓 度,在好氧 $3 \mathrm{~d}$, 厌氧 $7 、 14 、 30 \mathrm{~d}$ 时投放 DGT 装置,同步获取沉积物剖面 P、Fe 的信息.

1.3.3 样品分析方法 ZrO-Chelex DGT 固定膜中有效态 P 和 Fe 浓度的测定参考文献 [ 19]: 沿 DGT 装置暴露 窗口边缘划开, 取出固定膜, 用去离子水轻轻冲洗后吸去残留水, 然后置于陶瓷组刀上将膜切成 $1 \mathrm{~mm}$ 宽的 长条, 于 $400 \mu \mathrm{l} 1 \mathrm{~mol} / \mathrm{L}$ 的 $\mathrm{HNO}_{3}$ 提取液中, $16 \mathrm{~h}$ 后吸出提取液, 待测有效态 $\mathrm{Fe}$; 固定膜长条加人 $400 \mu \mathrm{l}$ 去离 
子水取出残留 $\mathrm{HNO}_{3}$, 加人 $400 \mu \mathrm{l} 1 \mathrm{~mol} / \mathrm{L} \mathrm{NaOH}$ 提取液, $16 \mathrm{~h}$ 后吸出提取液, 待测有效态 $\mathrm{P}$ 浓度. 提取液中 $\mathrm{PO}_{4}^{3-}$ 和 $\mathrm{Fe}^{2+}$ 浓度的测定分别采用钼蓝和邻菲罗啉微量比色法 ${ }^{[29]}$.

沉积物分析方法: 将不同湖区的沉积物带回实验室后, 称取约 $2 \mathrm{~g}$ 沉积物样品烘干测定含水率. 剩余样 品封袋后马上进行低温冷冻, 再将冻土进行冷冻干燥, 研磨过篮后装人自封袋中待分析. 沉积物各指标均按 照标准分析方法分析 ${ }^{[30]}$. 烧失量 ( LOI) 通过在 $550^{\circ} \mathrm{C}$ 环境下灼烧沉积物 $6 \mathrm{~h}$ 测定; 元素含量测定采用 $\mathrm{LiBO}_{2}$ 消解法, 提取液中总磷含量采用钼蓝显色法测定, 其他金属离子含量用 ICP-AES 进行测定.

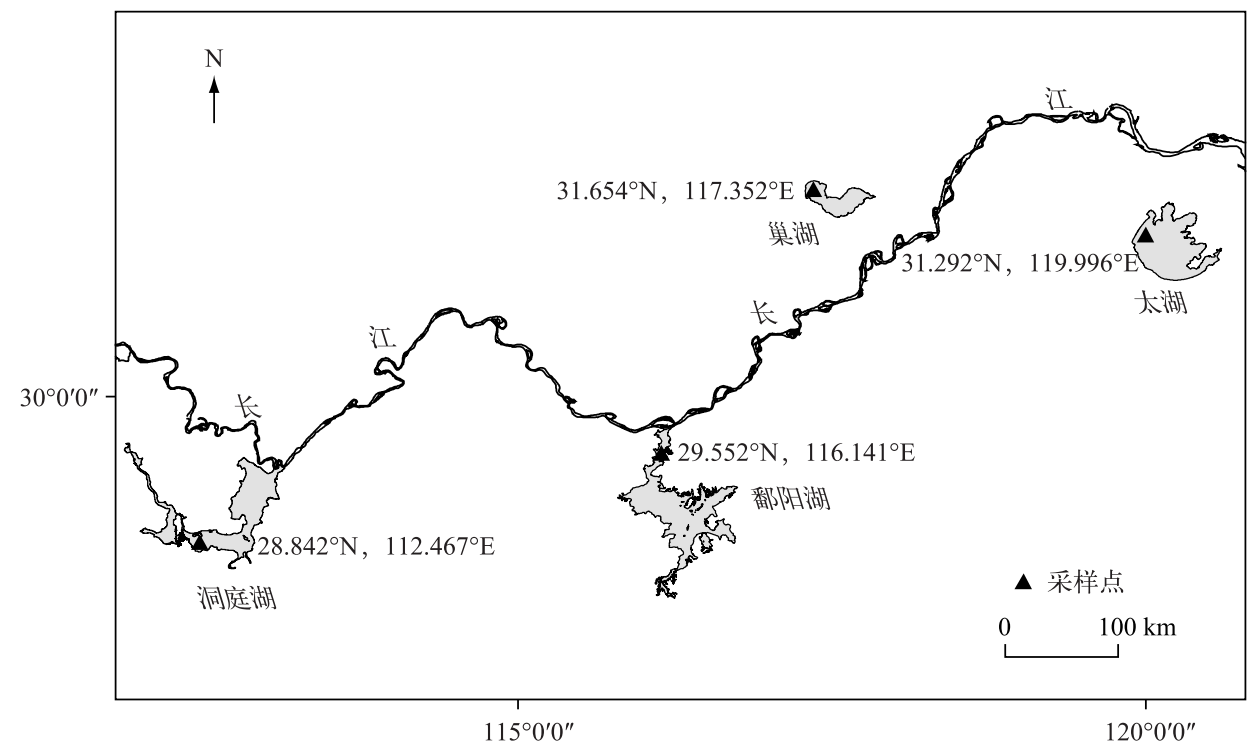

图 1 采样点分布

Fig.1 Distribution of sampling sites

\section{4 数据处理和分析}

根据 $\mathrm{PO}_{4}^{3-}$ 和 $\mathrm{Fe}^{2+}$ 微量比色的标准曲线, 得到提取液中 $\mathrm{P}$ 和 $\mathrm{Fe}$ 的浓度, 两者的累积量 $M$ 为:

$$
M=\frac{C_{\mathrm{e}}\left(V_{\mathrm{e}}+V_{\mathrm{g}}\right)}{f_{\mathrm{e}}}
$$

式中, $C_{\mathrm{e}}$ 为提取液中 $\mathrm{P}$ 和 $\mathrm{Fe}$ 的浓度, $V_{\mathrm{e}}$ 和 $V_{\mathrm{g}}$ 分别为提取液和固定膜的体积, $f_{\mathrm{e}}$ 为提取率, ZrO-Chelex 固定膜 $\mathrm{P}$ 和 $\mathrm{Fe}$ 的提取率分别为 $96 \%$ 和 $88 \%$.

有效态 $\mathrm{P}$ 和 $\mathrm{Fe}$ 浓度可依据公式 (2) 得到:

$$
C_{\mathrm{DGT}}=\frac{M \cdot \Delta g}{D_{\mathrm{g}} \cdot A \cdot t}
$$

式中, $C_{\mathrm{DGT}}$ 为沉积物剖面有效态浓度的平均值 ${ }^{[31]} ; \Delta g$ 为扩散层厚度 $(\mathrm{cm}) ; D_{\mathrm{g}}$ 为 $\mathrm{PO}_{4}^{3-}$ 和 $\mathrm{Fe}^{2+}$ 在扩散层中的扩 散系数, 分别为 6.86 和 $6.40\left(\times 10^{-6} \mathrm{~cm}^{2} / \mathrm{s}, 25^{\circ} \mathrm{C}\right)$, 其值可参考文献 $[32] ; A$ 为条状固定膜的面积 $\left(\mathrm{cm}^{2}\right) ; t$ 为 扩散时间 $(\mathrm{s})$.

\section{2 结果与讨论}

\section{1 沉积物理化性质}

4 个湖泊采样点表层沉积物的元素含量组成如表 1 所示, $\mathrm{Al}$ 和 $\mathrm{Fe}$ 含量最高, 分别为 $64.9 \sim 75.7 \mathrm{mg} / \mathrm{g}$ 和 $31.8 \sim 48.4 \mathrm{mg} / \mathrm{g}$, 其数值超过其他元素一个数量级. $\mathrm{Ca}$ 含量仅次于 $\mathrm{Al}$ 和 $\mathrm{Fe}$, 为 $2.1 \sim 6.4 \mathrm{mg} / \mathrm{g}$. $\mathrm{Mn}$ 在沉积物 表层中的含量最低, 为 $0.82 \sim 1.3 \mathrm{mg} / \mathrm{g}$. 沉积物总磷含量为 $0.54 \sim 0.84 \mathrm{mg} / \mathrm{g}$, 在各个湖泊的次序为洞庭湖>太 湖>巢湖>鄱阳湖. LOI 表征沉积物中有机质含量 ${ }^{[33]}$,太湖、巢湖、鄱阳湖和洞庭湖的 LOI 分别为 $4.7 \% 、 6.8 \%$ 、 
$6.6 \%$ 和 $4.9 \%$. 研究表明, $\mathrm{Fe} / \mathrm{P}$ 比值可表征沉积物对内源磷负荷的控制能力 ${ }^{[34]}$, 当 $\mathrm{Fe} / \mathrm{P}$ 比值为 $10 \sim 15$ 时, 由于铁 (氢) 氧化物对磷的控制作用, 内源 $\mathrm{P}$ 不足以释放. 本研究 4 个湖泊 $\mathrm{Fe} / \mathrm{P}$ 比值分别为 $71 、 52 、 59$ 和 46, 表明所选采样点的沉积物内源磷的风险较小.

表 14 个湖泊表层沉积物的基本理化性质

Tab.1 Basic physicochemical properties of sampling sites of the four lakes

\begin{tabular}{|c|c|c|c|c|c|c|c|}
\hline \multirow{2}{*}{ 采样点 } & \multicolumn{5}{|c|}{ 元素含量/( mg/g) } & \multirow{2}{*}{ LOV $\%$} & \multirow{2}{*}{$\mathrm{Fe} / \mathrm{P}$} \\
\hline & $\mathrm{Al}$ & $\mathrm{Ca}$ & $\mathrm{Fe}$ & $\mathrm{Mn}$ & $\mathrm{P}$ & & \\
\hline 太湖 & 70.3 & 4.2 & 48.8 & 1.2 & 0.69 & 4.7 & 71 \\
\hline 巢湖 & 64.9 & 4.8 & 32.7 & 1.3 & 0.64 & 6.8 & 52 \\
\hline 鄱阳湖 & 75.7 & 2.1 & 31.8 & 0.82 & 0.54 & 6.6 & 59 \\
\hline 洞庭湖 & 73.6 & 6.4 & 38.5 & 1.3 & 0.84 & 4.9 & 46 \\
\hline
\end{tabular}

\section{2 沉积物有效态 $P$ 和 $F e$ 的分布特征}

4 个湖泊沉积物剖面 DGT 有效态 P 和 Fe 浓度分布如图 2 所示. 太湖、巢湖、鄱阳湖和洞庭湖的有效态 $\mathrm{P}$ 浓度均在沉积物一水界面处增加, 分别在 $-14,-10 、-19$ 和 $-26 \mathrm{~mm}$ 处达到第 1 个峰值, 且不同湖区沉积物峰 值处有效态 $\mathrm{P}$ 的浓度不一, 其中在鄱阳湖和洞庭湖浓度较高, 分别为 0.41 和 $0.52 \mathrm{mg} / \mathrm{L}$, 与鄱阳湖和洞庭湖 湖泊富营养化情况更为严峻一致 ${ }^{[22]}$. 有效态 $\mathrm{P}$ 到达第一个峰值后继续波动变化, 在不同深度达到峰谷值, 且峰谷值数不一. 峰值区域表明间隙水中有效态 $\mathrm{P}$ 浓度的增加 ${ }^{[35]}$. 相应地, 谷值区域可能为有效态 $\mathrm{P}$ 的释 放衰减, 且可能与细菌等微生物对有机质的降解有关, 这种减少在时间上会持续到细菌衰亡 ${ }^{[36-37]}$. 另外太湖 和巢湖沉积物剖面有效态 $\mathrm{P}$ 浓度的垂向变化更为明显, 这表明这两个湖泊沉积物异质性较强 ${ }^{[38]}$. 有效态 $\mathrm{P}$ 浓度分别在太湖、巢湖和洞庭湖沉积物剖面的 $-53,-79$ 和 $-56 \mathrm{~mm}$ 处趋于平缓, 且浓度值较高, 可能与下层 的还原环境有关系 ${ }^{[39]}$.

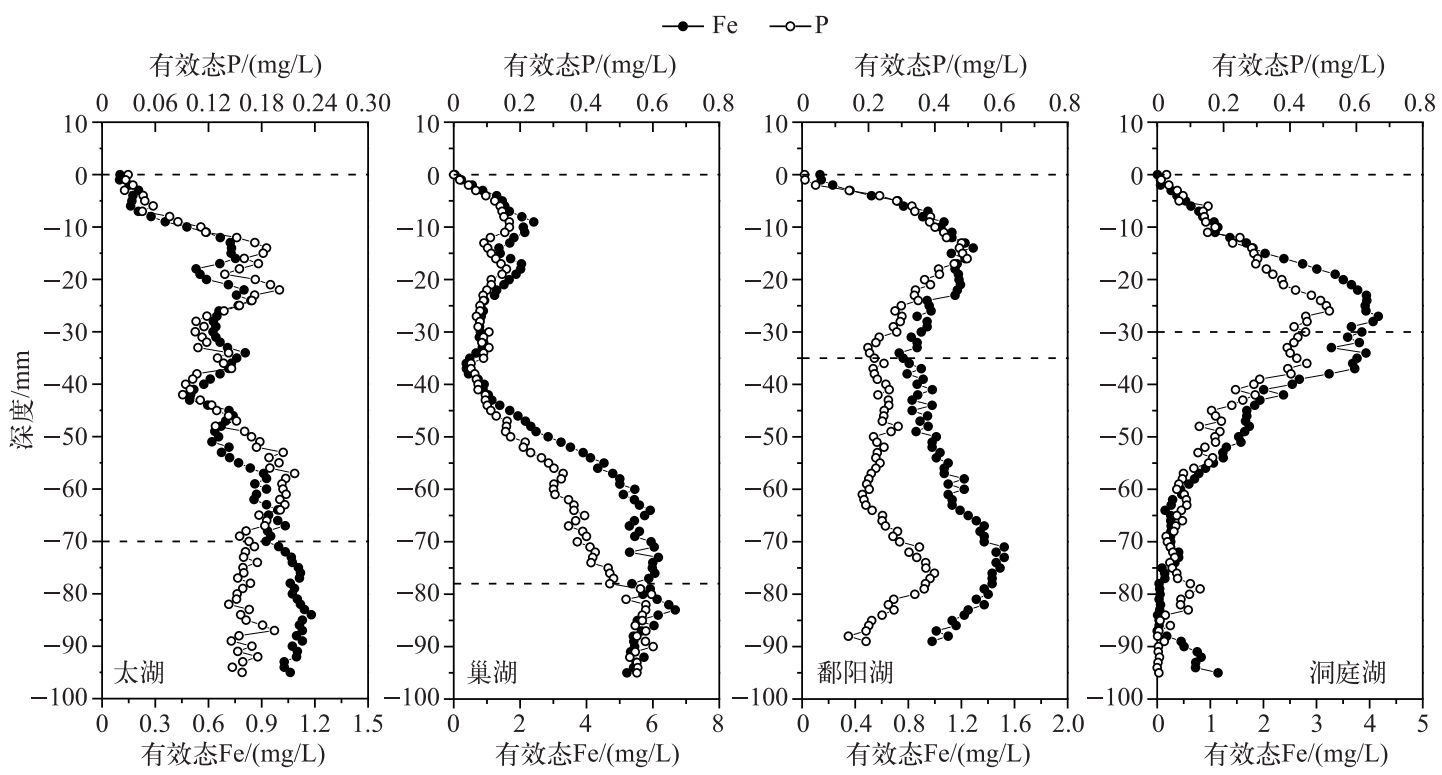

图 2 沉积物剖面有效态 $\mathrm{P}$ 和 $\mathrm{Fe}$ 浓度分布

Fig.2 Vertical distributions of labile $\mathrm{P}$ and $\mathrm{Fe}$ in the sediments profile

4 个湖泊沉积物剖面有效态 $\mathrm{Fe}$ 浓度范围变化较大, 其增减幅度在峰谷处明显于有效态 $\mathrm{P}$ 浓度的增减幅 度, 这与 Ding 等 ${ }^{\left[{ }^{[0]}\right.}$ 对太湖沉积物的原位测定结果一致. 与有效态 $\mathrm{P}$ 浓度在沉积物剖面分布类似, 有效态 $\mathrm{Fe}$ 
浓度在沉积物剖面的垂向分布规律与有效态 $\mathrm{P}$ 一致,两者均在沉积物一水界面处增加, 并在相同深处波动变 化, 呈现同步升高或降低的趋势.

对上述 4 个剖面有效态 $\mathrm{P}$ 和 $\mathrm{Fe}$ 浓度变化明显区域 (虚线界定区域) 进行相关性分析, 结果见图 3.4 个 湖泊沉积物剖面有效态 $\mathrm{P}$ 和 $\mathrm{Fe}$ 浓度具有显著的正相关关系 $(P<0.05)$, 表明沉积物中磷与铁均存在明显的 耦合关系, 磷释放受铁还原的控制, 即好氧条件下 $\mathrm{Fe}^{2+}$ 被氧化为 $\mathrm{Fe}^{3+}$, 所生成的 (氢) 氧化铁吸附固定磷, $\mathrm{Fe}$ 和 $\mathrm{P}$ 同步减少; 戻氧条件下 $\mathrm{Fe}^{3+}$ 被还原为 $\mathrm{Fe}^{2+}$, 溶解释放 $\mathrm{Fe}^{2+}$ 和 $\mathrm{P}$, 有效态 $\mathrm{Fe}$ 和 $\mathrm{P}$ 同步增加 ${ }^{[41]}$. 线性方程的 斜率表征沉积物中有效态 $\mathrm{Fe}$ 对 $\mathrm{P}$ 迁移的能力 ${ }^{[40]}$. 在太湖和鄱阳湖沉积物中, 有效态 $\mathrm{Fe}$ 和 $\mathrm{P}$ 浓度比值的斜 率较低(3.96 和 2.21), 表明这两个湖泊沉积物中活性氧化铁浓度较低, 沉积物剖面有效态 $\mathrm{P}$ 释放能力较 强 ${ }^{[0]}$. 而在巢湖和洞庭湖中, 其斜率值较高 (14.25 和 9.18), 说明沉积物中对 P 的固定能力较强.
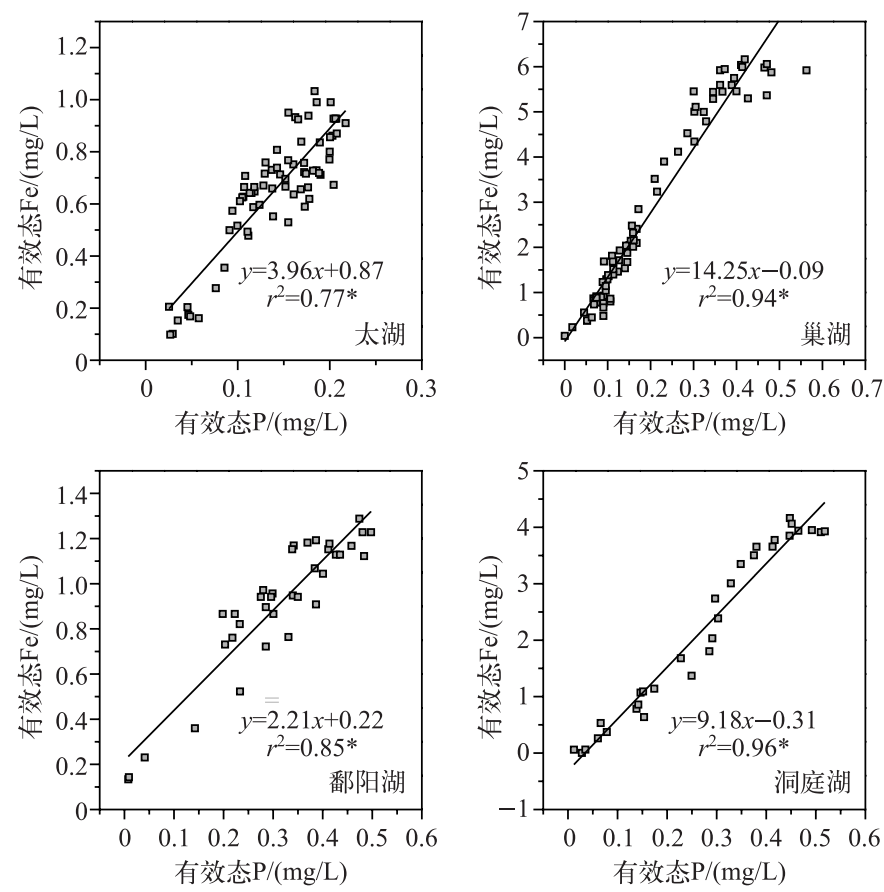

图 3 沉积物有效态 $\mathrm{P}$ 和 $\mathrm{Fe}$ 的相关性 $(*$ 表示相关性显著,下同)

Fig. 3 Correlation analyses between labile $\mathrm{P}$ and $\mathrm{Fe}$ in sediments

\section{3 沉积物一水界面磷铁同步释放机制分析}

通过室内模拟好氧一庆氧环境, 发现在沉积物厌氧过程中, 有效态 $\mathrm{P}$ 和 $\mathrm{Fe}$ 浓度均在 $-10 \mathrm{~mm}$ 左右处开始 增加, 于-40 -50 mm 处达到峰值, 且保持峰值的较高浓度, 向下停止减少; 随着厌氧过程的加剧, 有效态 $\mathrm{P}$ 和 $\mathrm{Fe}$ 浓度逐渐同步升高 (图 4). 可见, 随着沉积物内部还原环境的加强, 铁不断还原, $\mathrm{Fe}^{3+}$ 被持续还原为 $\mathrm{Fe}^{2+}$, 铁结合态的磷也随之释放, 导致了磷的释放量也逐渐增加. 进一步分析不同厌氧条件下沉积物剖面有 效态 P 和 Fe 浓度变化明显区域 (虚线界定区域) 的相关性, 发现均呈显著或极显著的正相关, 即两者在沉积 物剖面存在同步释放的规律 (图 5). 室内厌氧培养实验进一步证实了磷铁之间的耦合关系, 即铁的还原导 致磷的释放. Ding 等 ${ }^{[40]}$ 对太湖 14 个位点进行原位测定, 均发现沉积物剖面有效态 P 和 Fe 的释放具有同步 性, 与本研究的结果一致, 很可能说明磷铁同步释放普遍存在于长江中下游湖泊. Rydin 等 $^{[42]}$ 对波罗的海海 岸沉积物界进行 $\mathrm{P}$ 释放机理探索, 发现潜在活性 $\mathrm{P}$ 的释放主要受 $\mathrm{Fe}-\mathrm{P}$ 控制, 即 $\mathrm{P}$ 的释放受 $\mathrm{Fe}$ 的氧化还原 控制 ${ }^{[41,43]}$. 可能的原因是 $\mathrm{Fe}^{3+}$ 浓度的增加, 会降低 $\mathrm{P}$ 的迁移性 ${ }^{[4]}$. 另外, $\mathrm{Fe}^{2+}$ 浓度的减少, 不仅仅受氧化还原 环境的变化影响, 也可能是硝酸或硫酸酶含量减少所致 ${ }^{[45]}$, 硝酸盐细菌呼吸作用的增强, 能够增加沉积物中 $\mathrm{Fe}-\mathrm{P}$ 络合物中 $\mathrm{P}$ 释放的速率 ${ }^{[46]}$. 同时, 硝酸盐细菌的分泌物也能够加速 $\mathrm{Fe}^{3+}$ 的溶解, 使吸附在 $\mathrm{Fe}(\mathrm{OH})_{3}$ 中 
的 $\mathrm{P}$ 释放出来 ${ }^{[47]}$.

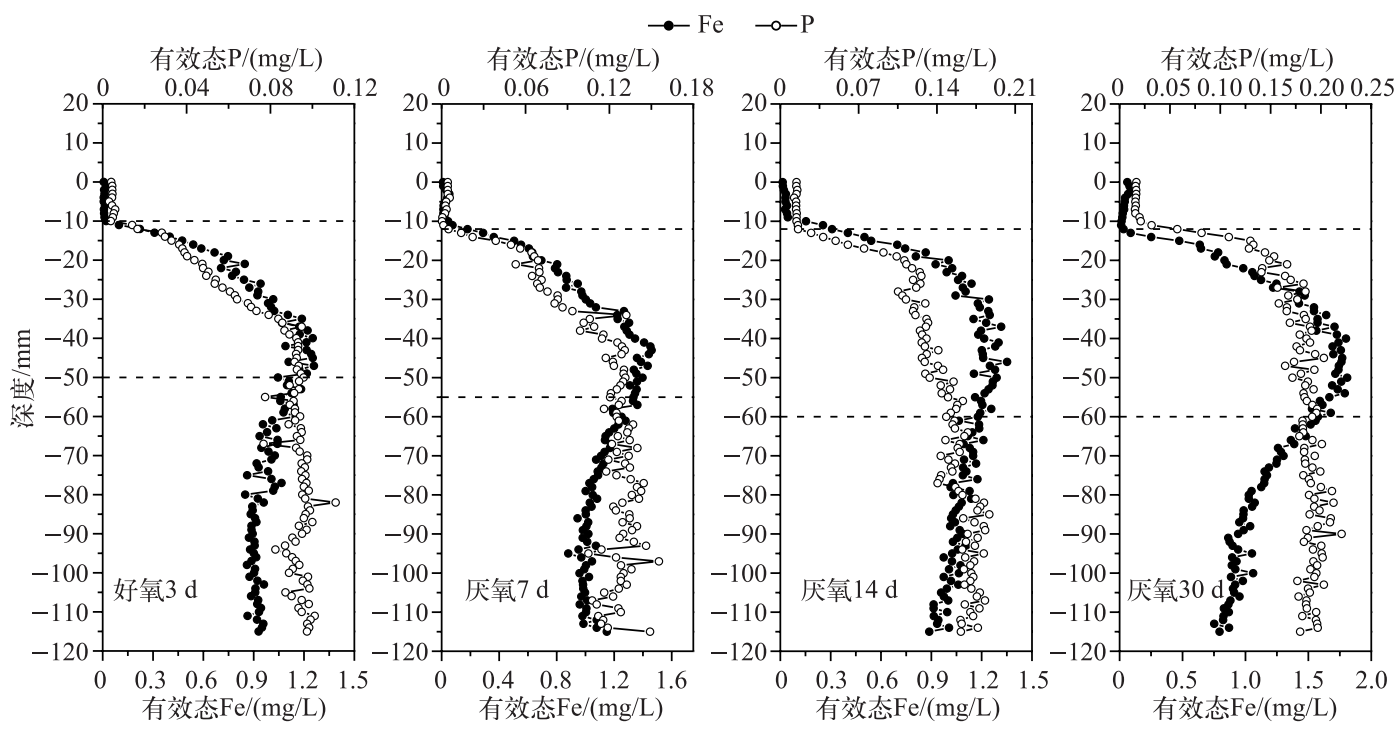

图 4 好氧一庆氧过程沉积物剖面有效态 $\mathrm{P}$ 和 $\mathrm{Fe}$ 的浓度分布

Fig.4 Distributions of labile $\mathrm{P}$ and $\mathrm{Fe}$ in the sediments during anaerobic-aerobic incubation
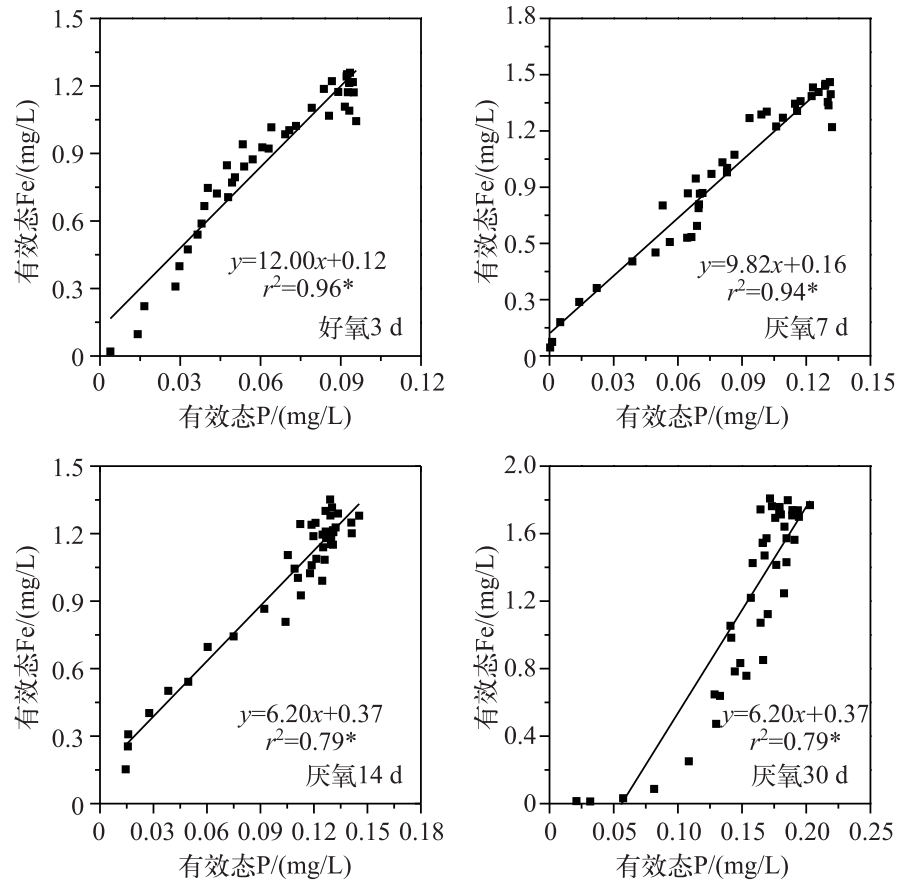

图 5 好氧- 厌氧过程沉积物有效态 $\mathrm{P}$ 和 $\mathrm{Fe}$ 的相关性

Fig.5 Correlation analyses between labile $\mathrm{P}$ and Fe during anaerobic-aerobic incubation

\section{3 结论}

1) 不同湖泊沉积物理化性质差异较大, 且磷铁含量在沉积物垂向分布具有较大的空间异质性, 不同湖 
泊异质性也存在差异.

2) 沉积物中磷和铁存在堣合关系, 磷、铁含量呈现同步增加或减少的趋势, 4 个湖泊沉积物均存在相同 的变化规律.

3) 室内好氧一厌氧培养实验验证了铁磷耦合关系, 即铁的还原可导致磷释放, 沉积物磷的二次迁移主 要受铁氧化还原过程的控制.

\section{4 参考文献}

[ 1 ] Sondergaard M, Jensen PJ, Jeppesen E. Retention and internal loading of phosphorus in shallow, eutrophic lakes. Scientific World Journal, 2001, 1(1/2/3) : 427-442. DOI: 10.1100/tsw.2001.72.

[ 2 ] Xiao Yonghui. Continues online monitoring of eutrophication and early warning of cyanobacteria bloom in Chaohu lake [Dissertation]. Yangzhou: Yangzhou University, 2011. [ 肖永辉. 巢湖富营养化连续在线监测与蓝藻水华预警 [学位 论文]. 扬州: 扬州大学, 2011.]

[ 3 ] Wang Yan. Spatial and temporal distribution of nitrogen and phosphorus and ecological risk assessment of Dongting Lake [Dissertation]. Harbin: Northeast Forestry University, 2014. [王岩. 洞庭湖氮磷时空分布及生态风险评价 [ 学位论 文]. 哈尔滨: 东北林业大学, 2014.]

[ 4 ] Cheng Fang. The study of eutrophication condition and aquatic community structure of Taihu Lake[Dissertation]. Suzhou: Soochow University, 2010. [ 成芳. 太湖水体富营养化与水生生物群落结构的研究 [学位论文]. 苏州: 苏州大 学, 2010.]

[ 5 ] Sundareshwar PV, Morris JT, Koepfler EK et al. Phosphorus limitation of coastal ecosystem processes. Science, 2003,299 (5606) : 563-565. DOI: 10.1126/science.1079100.

[ 6 ] Cullen P, Forsberg C. Experiences with reducing point sources of phosphorus to lakes. Hydrobiologia, 1988, 170(1) : 321-336. DOI: 10.1007/BF00024912.

[ 7 ] Redshaw CJ, Mason CF, Hayes CR et al. Factors influencing phosphate exchange across the sediment-water interface of eutrophic reservoir. Hydrobiologia, 1990, 192(2) : 233-245. DOI: 10.1007/BF00006018.

[ 8 ] Xu D, Chen Y, Ding S et al. Diffusive gradients in thin films technique equipped with a mixed binding gel for simultaneous measurements of dissolved reactive phosphorus and dissolved iron. Environmental Science \& Technology, 2013,47 (18) : 10477-10484. DOI: 10.1021/es401822x.

[ 9 ] Meng Fande. Study on the relationship between physical and chemical properties and phosphorus along with their forms in the sediment of the mid-lower Yangtze Lakes [ Dissertation]. Beijing: Capital Normal University, 2005. [孟凡德. 长江中 下游湖泊沉积物理化性质与磷及其形态的关系研究 [ 学位论文]. 北京: 首都师范大学, 2005.]

[10] Stockdale A, Davison W, Zhang H. High-resolution two-dimensional quantitative analysis of phosphorus, vanadium and arsenic, and qualitative analysis of sulfide, in a freshwater sediment. Environmental Chemistry, 2008, 5(2) : 143-149. DOI: $10.1071 /$ EN07096.

[11] Jing L, Liu X, Bai S et al. Effects of sediment dredging on internal phosphorus: A comparative field study focused on iron and phosphorus forms in sediments. Ecological Engineering, 2015, 82: 267-271. DOI: 10.1016/j.ecoleng.2015.04.099.

[12] Cesbron F, Metzger E, Launeau P et al. Simultaneous 2D imaging of dissolved iron and reactive phosphorus in sediment porewaters by thin-film and hyperspectral methods. Environmental Science \& Technology, 2014, 48(5) : 2816-2826. DOI: $10.1021 / \mathrm{es} 404724 \mathrm{r}$.

[13] Bortleson GC, Lee GF. Phosphorus, iron, and manganese distribution in sediment cores of six Wisconsin lakes 1. Limnology \& Oceanography, 1974, 19(5): 794-801.

[14] Ostrofsky ML. Phosphorus species in the surficial sediments of lakes of eastern north America. Canadian Journal of Fisheries \& Aquatic Sciences, 2011, 44(5): 960-966. DOI: 10.1139/f87-114.

[15] Søndergaard M, Windolf J, Jeppesen E. Phosphorus fractions and profiles in the sediment of shallow Danish lakes as related to phosphorus load, sediment composition and lake chemistry. Water Research, 1996, 30(4) : 992-1002. DOI: 10. 1016/0043-1354(95) 00251-0.

[16] Smolders AJP, Lamers LPM, Moonen M et al. Controlling phosphate release from phosphate-enriched sediments by adding various iron compounds. Biogeochemistry, 2001, 54(2) : 219-228. DOI: 10.1023/A : 1010660401527. 
[17] Amirbahman A, Pearce AR, Bouchard RJ et al. Relationship between hypolimnetic phosphorus and iron release from eleven lakes in Maine, USA. Biogeochemistry, 2003, 65(3) : 369-386. DOI: 10.1023/A :1026245914721.

[18] Lange GJD, Cranston RE, Hydes DH et al. Extraction of pore water from marine sediments: A review of possible artifacts with pertinent examples from the North Atlantic. Marine Geology, 1992, 109(1/2) : 53-76. DOI: 10.1016/0025-3227 (92) 90220-C.

[19] Xu D, Chen Y, Ding S et al. Diffusive gradients in thin films technique equipped with a mixed binding gel for simultaneous measurements of dissolved reactive phosphorus and dissolved iron. Environmental Science \& Technology, 2013,47 (18) : 10477-10484. DOI : 10.1021/es401822x.

[20] Sun Q, Zhang L, Ding S et al. Evaluation of the diffusive gradients in thin films technique using a mixed binding gel for measuring iron, phosphorus and arsenic in the environment. Environmental Science Processes \& Impacts, 2015, 17(3): 1143-1147. DOI: 10.1039/c4em00629a.

[21] Wang Qi. Study on the biological mechanism of phosphorus release from sediments in the shallow lakes [Dissertation]. Xi'an: Northwest A \& F University, 2006. [王琦. 浅水湖泊沉积物磷释放的生物学机制研究 [学位论文]. 西安: 西 北农林科技大学, 2006.]

[22] Zhang Binliang. The characteristics of phosphorus behavior at sediment-water interface and environmental risk assessment from sallow lakes [Dissertation]. Shanghai : East China Normal University, 2004. [张斌亮. 浅水湖泊沉积物一水界面磷 的行为特征与环境风险评价 [学位论文]. 上海: 华东师范大学, 2004.]

[23] Davison W, Zhang H. Progress in understanding the use of diffusive gradients in thin films (DGT) -back to basics. Environmental Chemistry, 2012, 9(1): 1-13. DOI: 10.1071/EN11084.

[24] Zhang C, Ding S, Xu D et al. Bioavailability assessment of phosphorus and metals in soils and sediments: a review of diffusive gradients in thin films (DGT). Environmental Monitoring \& Assessment, 2014, 186(11): 7367-7378. DOI: 10. 1007/s10661-014-3933-0.

[25] Ding S, Xu D, Sun Q et al. Measurement of dissolved reactive phosphorus using the diffusive gradients in thin films technique with a high-capacity binding phase. Environmental Science \& Technology, 2010, 44(21) : 8169-8174. DOI: 10. 1021/es1020873.

[26] Ding S, Xu D, Wang Y et al. Simultaneous measurements of eight oxyanions using high-capacity diffusive gradients in thin films (Zr-oxide DGT) with a high-efficiency elution procedure. Environmental Science \& Technology, 2016, 50(14): 7572-7580. DOI: 10.1021/acs.est.6b00206.

[27] Chen M, Ding S, Zhang L et al. An investigation of the effects of elevated phosphorus in water on the release of heavy metals in sediments at a high resolution. Science of the Total Environment, 2017, 575: 330-337. DOI: 10.1016/j. scitotenv. 2016.10.063.

[28] Ding SM, Wang Y, Zhang LP et al. New holder configurations for use in diffusive gradients in thin films (DGT) technique. RSC Advance, 2016, 6(91) : 88143-88156. DOI: 10.1039/c6ra19677b.

[29] Wang Yan, Zhu Chungang, Xu Di et al. Development of a method for measurement dissolved reactive phosphorus (DRP) and dissolved ferrous iron in large batch in pore water samples of sediments with micro-volumes. Environmental Science, 2014, 35(4) : 1271-1277. [王燕, 朱春刚, 许笛等. 一种大批量测定沉积物微量间隙水样品中溶解态磷和铁含量 的方法. 环境科学, 2014, 35(4) : 1271-1277.]

[30] Lu Rukun ed. Soil agricultural chemical analysis method. Beijing: China Agriculture Scientech Press, 2000. [鲁如坤. 土 壤农业化学分析方法. 北京: 中国农业科技出版社, 2000.]

[31] Luo Jun, Wang Xiaorong, Zhang Hao et al. Theory and application of diffusive gradients in thin films in soils. Journal of Agro-Environment Science, 2011, 30(2) : 205-213. [罗军, 王晓蓉, 张吴等. 梯度扩散薄膜技术( DGT) 的理论及其 在环境中的应用 I:工作原理、特性与在土壤中的应用. 农业环境科学学报, 2011, 30(2): 205-213.]

[32] Li YH, Gregory S. Diffusion of ions in sea water and in deep-sea sediments. Geochimica et Cosmochimica Acta, 1974, 38 ( 5) : 703-714.

[33 ] Liu Ziting, Yu Junqing, Zhang Baohua et al. Application of loss on ignition to the study of lake sediments and environmental changes. Journal of Salt Lake Research, 2006, 14(2): 67-72. [刘子亭, 余俊清, 张保华等. 烧失量分析在湖泊沉 积与环境变化研究中的应用. 盐湖研究, 2006, 14(2) : 67-72.]

[34] Caraco NF, Cole JJ, Likens GE. Sulfate control of phosphorus availability in lakes. Hydrobiologia, 1993, 253(1) : 275- 
280. DOI: $10.1016 /$ j. scitotenv.2015.10.155.

[35] Wang Yanping, Guan Qingwei, Li Chao et al. A study of in situ synchronous measurement of available phosphorus and sulfur in the sediments of lake Chaohu by diffusive gradients in thin films(DGT). Acta Scientiae Circumstantiae, 35(8): 2512-2518. DOI: 10.13671/j.hjkxxb.2014.0996. [王艳平, 关庆伟, 李超等. 巢湖沉积物有效态磷与硫的 DGT 原位 同步分析研究. 环境科学学报, 2015, 35(8): 2512-2518.]

[36] Tezuka Y. Bacterial regeneration of ammonium and phosphate as affected by the carbon: nitrogen: phosphorus ratio of organic substrates. Microbial Ecology, 1990, 19(3) :227-238. DOI: 10.1007/BF02017167.

[37] Hessen DO, Ågren GI, Anderson TR et al. Carbon sequestration in ecosystems: the role of stoichiometry. Ecology, 2004, 85(5) : 1179-1192. DOI: 10.1890/02-0251.

[38] Ding S, Chao H, Wang Y et al. In situ, high-resolution imaging of labile phosphorus in sediments of a large eutrophic lake. Water Research, 2015, 74: 100-109. DOI: 10.1016/j.watres.2015.02.008.

[39] Ding S, Wang Y, Xu D et al. Gel-based coloration technique for the submillimeter-scale imaging of labile phosphorus in sediments and soils with diffusive gradients in thin films. Environmental Science \& Technology, 2013, 47(14) : 7821-7829. DOI: $10.1021 / \mathrm{es} 400192 \mathrm{j}$.

[ 40] Ding S, Wang Y, Wang D et al. In situ, high-resolution evidence for iron-coupled mobilization of phosphorus in sediments. Scientific Reports, 2016. DOI: 10.1038/srep24341.

[41] Baccini P. Phosphate interactions at the sediment-water interface. In: Stumm W ed. Chemical processes in lakes. New York: Wiley-Interscience, 1985: 189-205.

[42] Rydin E, Malmaeus JM, Karlsson OM et al. Phosphorus release from coastal Baltic Sea sediments as estimated from sediment profiles. Estuarine Coastal \& Shelf Science, 2011, 92(1) : 111-117. DOI: 10.1016/j.ecss.2010.12.020.

[ 43] Mortimer CH. The exchange of dissolved substances between mud and water in lakes. I \& II J Ecol, 1941, 30( 21) : 147201. DOI: $10.2307 / 2256691$.

[44] Jones JGS, Gardener S, Simon BM. Bacterial reduction of ferric iron in a stratified eutrophic lake. Microbiology, 1983, 129(1) : 131-139. DOI: 10.1099/00221287-129-1-131.

[45] Sperber JI. Release of phosphate from soil minerals by hydrogen sulphide. Nature, 1958, 181(4613): 934. DOI: 10. 1038/181934a0.

[ 46] Jansson M. Nitrate as a catalyst for phosphorus mobilization in lake sediments. In: Sly PA ed. Sediments and water interactions. New York: Springer-Verlag, 1986: 382-387.

[47] Jansson M. Anaerobic dissolution of iron-phosphorus complexes in sediment due to the activity of nitrate-reducing bacteria. Microbial Ecology, 1987, 14(1) : 81-89. DOI: 10.1007/BF02011573. 